\title{
Responsabilidide Pelo Defeito de Medicamento: AnÁlise de Decisão da Corte de Cassação Francesa sob a Perspectiva do Direito do Consumidor Brasileiro
}

\author{
RESPONSIBILITY FOR DRUGS DEFEATS: AN ANALYSIS OF THE \\ DECISION OF FRENCH COURT UNDER THE PERSPECTIVE OF THE \\ BRAZILIAN CONSUMER LAW
}

Letícia Canut ${ }^{(*)}$

Após analisar três decisões da Corte de Apelação sobre responsabilidade do fabricante de medicamentos, a Corte de Cassação francesa pronunciou a decisão ora em comento. São brevemente relatados três casos envolvendo medicamentos "defeituosos".

O regime de responsabilidade nesta matéria é regido na França, para os produtos colocados em circulação a partir de julho de 1988, pelos arts. 1386-1 a 1386-18 do Código Civil. Estes dispositivos foram inseridos por meio da Lei n. 98-389, de maio de 1998, que transpôs a Diretiva da CEE 85/ 374 , relativa à responsabilidade sobre os produtos defeituosos, para o ordenamento nacional.

O primeiro caso avaliado diz respeito à condenação de laboratório em virtude do uso de seu medicamento ter provocado o desenvolvimento de hipertensão arterial e pulmonar no usuário e, consequentemente, o seu encaminhamento para uma cirurgia séria. Além deste fato, a Corte de Apelação analisou a possibilidade de incidência de responsabilidade do médico do trabalho que prescreveu o remédio, tendo afastado a sua responsabilidade.

Diante desta decisão, a Corte de Cassação manteve a condenação do laboratório e o posicionamento da Corte de Apelação com relação à existência de um nexo de causalidade entre o dano provocado e a administração do medicamento. No entanto, ressaltou que a prova do nexo causal deveria pautar-se não na simples hipótese acerca da causa do prejuízo, mas em presunções graves, precisas e concordantes. Acerca da responsabilidade do médico do trabalho, a Corte de Cassação anulou a decisão da Corte de Apelação, destacando que ele havia agido de forma a extrapolar as suas atribuições, que eram preventivas. Assim, ressaltou que esta falta pode ser invocada pelo paciente para responsabilizar o médico.

( ${ }^{*}$ ) Mestre em Direito pela Universidade Federal de Santa Catarina (UFSC) e professora Universitária. 
O segundo caso sob análise da Corte de Cassação, específico sobre a caracterização do defeito do produto, é uma decisão da Corte de Apelação que responsabilizou o fabricante de uma vacina considerando-a o fator desencadeador do aparecimento da síndrome de Guillain-Barré. Foi considerado ainda que as informações fornecidas quando da autorização do produto citavam a possibilidade de "efeitos indesejáveis" por meio das quais muito raramente eram mencionadas neuropatias periféricas.

A Corte de Cassação invalidou esta decisão pronunciando que estas constatações eram insuficientes para caracterizar o "defeito do produto" e a consequente responsabilidade do fabricante pelo dano causado. Esta deliberação pautou-se no fato de que o produto, quando colocado em circulação, oferecia a segurança que dele se podia legitimamente esperar, considerando todas as circunstâncias, dentre elas a sua apresentação. Desta forma, a mais alta Corte francesa considerou que o fato de a vacina ser fator desencadeador da síndrome não provava o defeito do produto, mas apenas a existência de efeitos indesejáveis.

O terceiro caso é relativo à contaminação por meio de hormônio de crescimento. Primeiramente, a Corte de Cassação aprovou o posicionamento da Corte de Apelação por ter descartado a prescrição prevista no art. 11 da diretiva 85/374, de 24 de julho de 1985, segundo o qual os direitos da vítima contra o produtor se extinguem em 10 anos depois que o produto é colocado em circulação. Considerando que os produtos foram colocados no mercado em fevereiro de 1985, a Corte de Cassação reafirma o entendimento da Corte de Apelação de que na época a diretiva não estava em vigor e que o regime de responsabilidade em causa advém unicamente das disposições nacionais, dos arts. 1.347 e 1.382 do Código Civil francês.

A Corte de Cassação ponderou ainda o fato de a Corte de Apelação ter considerado que existiam presunções graves, precisas e concordantes para provar o nexo de causalidade entre a doença contraída pela vítima e o hormônio de crescimento que Ihe foi administrado, principalmente diante da circunstância de que todos os pacientes que utilizaram o hormônio tinham contraído a mesma doença.

Após criticar e rejeitar as tentativas de afastar a responsabilidade do fabricante do medicamento por meio da aplicação das cláusulas exoneratórias da diretiva de 1985, como a relativa ao estado de conhecimentos científicos e técnicos no momento da colocação do produto em circulação, a Corte de Cassação manteve a decisão da Corte de Apelação no sentido de responsabilizar o fabricante pelo fato de ele não ter seguido as precauções recomendadas para a extração, a purificação e a composição dos hormônios de crescimento, e de que existia um nexo de causalidade direto entre esta falta de prudência e a contaminação da vítima.

Por meio do presente trabalho, pretende-se analisar os pronunciamentos da Corte de Cassação francesa, ora transcrita, sob a perspectiva da responsabilidade civil objetiva prevista no direito do consumidor brasileiro - que foi inserida no ordenamento nacional por influência direta da diretiva 
85/374 da CEE $^{(1)}$ - de forma a ressaltar algumas conexões entre este ramo do direito e o direito à saúde. Os interesses comuns entre estas áreas são evidentes e de fácil constatação. No entanto, falta, ainda, comunicação entre elas e entre os pesquisadores de cada uma delas.

A Constituição Federal de 1988 reconheceu pela primeira vez no Brasil, o direito à saúde como um direito social fundamental (art. 6ํ, CF), que deve ser garantido pelo Estado a todos (art. 196, CF) por meio de um Sistema Único de Saúde - SUS fundamentado nos princípios de universalidade, de equidade e de integralidade (art. 196, CF) e organizado com base nas diretrizes de descentralização, de regionalização e hierarquização, e de participação da comunidade (art. 198, CF) ${ }^{(2)}$.

Para garantir este direito, o Estado passou a legislar para organizar o Sistema Único de Saúde. Foram promulgadas, inicialmente, a Lei n. 8.080/90 e a Lei n. 8.142/90. Na sequência, foram elaboradas Normas Operacionais do SUS - NOBs, Normas de Organização da Assistência à Saúde - Noas, outras leis, decretos e portarias. Em decorrência da difusão de normas voltadas para a proteção da saúde, emergiu um novo ramo do direito, o direito sanitário ${ }^{(3)}$.

Ressalta-se que a Lei n. 8.080/90 passa a abordar a "saúde" de forma mais abrangente, em conformidade com o conceito proposto pela $\mathrm{OMS}^{(4)}$, como:

Art. $3^{\circ}$ A saúde tem como fatores determinantes e condicionantes, entre outros, a alimentação, a moradia, o saneamento básico, o meio ambiente, o trabalho, a renda, a educação, o transporte, o lazer e o acesso aos bens e serviços essenciais; os níveis de saúde da população expressam a organização social e econômica do País.

Parágrafo único. Dizem respeito também à saúde as ações que, por força do disposto no artigo anterior, se destinam a garantir às pessoas e à coletividade condições de bem-estar físico, mental e social.(5)

A Constituição Federal de 1988 também dispôs claramente sobre a proteção do consumidor. Os dispositivos que fazem referência ao tema e que costumam ser mais citados são: o inciso XXXII do art. 5ㅇ, que dispõe que "o Estado promoverá, na forma da lei, a defesa do consumidor"(6); o inciso V do

(1) BENJAMIN, Antônio Herman de Vasconcellos e. O código brasileiro de proteção ao consumidor. 1993. Disponível em: <http://bdjur.stj.gov.br/dspace/bitstream/2011/9471/1/O_C\%C3\%B3digo_ Brasileiro_Prote\%C3\%A7\%C3\%A3o_Consumidor.pdf>. Acesso em: jul. 2008.

(2) BRASIL. Constituição Federal de 1988. Disponível em: <http://www.planalto.gov.br/ccivil_03/ Constituicao/Constitui\%E7ao.htm>. Acesso em: ago. 2008.

(3) BRASIL. Manual de direito sanitário com enfoque na vigilância em saúde. Brasília: Ministério da Saúde, 2006.

(4) OLIVEIRA, Mariana Siqueira de Carvalho. Por uma construção democrática do direito à saúde: a Constituição Federal, os instrumentos de participação social e a experiência do Conselho Nacional de Saúde. 2005. Dissertação (Mestrado em Direito) - Programa de Pós-Graduação em Direito. Curso de Pós-Graduação em Direito, Universidade de Brasília, Brasília, 2005.

(5) BRASIL. Lei n. 8.080, de 13 de setembro de 1990. Dispõe sobre as condições para a promoção, proteção e recuperação da saúde, a organização e o funcionamento dos serviços correspondentes e dá outras providências. Disponível em: <http://www.planalto.gov.br/ccivil_03/Leis/L8080.htm>. Acesso em: jun. 2008.

(6) BRASIL. Constituição Federal de 1988, cit., p. 8. 
art. 170, que insere "a defesa do consumidor" entre os princípios que a ordem econômica deve observar ${ }^{(7)}$; o art. 48, do Ato das Disposições Transitórias, que prescreve que "o Congresso Nacional, dentro de cento e vinte dias da promulgação da Constituição, elaborará código de defesa do consumidor"(8). Em cumprimento a estas disposições foi promulgado o Código de Defesa do Consumidor - Lei n. 8.078 de setembro de 1990.

O Código de Defesa do Consumidor é um "microssistema jurídico de caráter "inter e multidisciplinar", que visa à defesa do consumidor desde a relação de consumo individual até a defesa dos interesses difusos; desde a simples propaganda à eventual lesão dos consumidores. Seu âmbito de atuação, como se vê, vai além da relação contratual, pois cuida de situações pré e pós-contratuais. Além de possuir seus próprios princípios, "no âmbito da chamada ciência consumerista", o CDC também "relaciona-se com outros ramos de Direito", renova antigos institutos, cuidando ainda de assuntos que dizem respeito a outras áreas do Direito, como o Direito Constitucional, o Civil, Penal, Processuais Civil e Penal e Administrativo(9) e Direito Sanitário.

Neste aspecto, tendo em vista o conceito de saúde supramencionado, percebe-se, sem necessidade de pesquisas e estudos aprofundados, que há grande vinculação entre esta área e a do direito do consumidor. E que ao proteger a saúde e segurança o CDC estabelece "critérios para tutela do bem mais valioso a ser preservado nas relações de consumo: a vida do consumidor"(10).

A relação entre a tutela do consumidor e a área de saúde, e mais especificamente a área de medicamentos, fica patente nos dizeres de DENARI:

[...] no que tange à tutela à saúde, os casos mais freqüentes de fornecimentos capazes de afetá-la se localizam na área dos alimentos e, principalmente, dos medicamentos, envolvendo os seus fabricantes, vale dizer, as indústrias e laboratórios, bem como os seus fornecedores imediatos, a saber, as farmácias, drogarias e hospitais. ${ }^{(11)}$

Procurar-se-á demonstrar de que forma o CDC tutela a saúde como um dos direitos básicos do consumidor para, num segundo momento, analisar a semelhança entre os dispositivos que fornecem o embasamento legal da decisão da Corte de Cassação francesa acerca da responsabilidade dos fabricantes de medicamentos com "defeito" e a responsabilidade pelo fato do produto prevista no Código de Defesa do Consumidor brasileiro.

(7) BRASIL. Constituição Federal de 1988, cit., p. 111.

(8) BRASIL. Constituição Federal de 1988, cit., p. 160; ALMEIDA, João Batista de. A proteção jurídica do consumidor. 2. ed. atual. e ampl. São Paulo: Saraiva, 2000. p. 11; FILOMENO, José Geraldo Brito. Dos direitos do consumidor. In: GRINOVER, Ada Pellegrini et al. Código de Defesa do Consumidor comentado pelos autores do anteprojeto. 7. ed. Rio de Janeiro: Forense, 2001. p. 22-23; NORONHA, Fernando. Direito do consumidor: contratos de consumo, cláusulas abusivas e responsabilidade do fornecedor. Apostila. [S.L.], [s.d.]. p. 8-9.

(9) FILOMENO, José Geraldo Brito. op. cit., p. 19-20.

(10) GRINOVER, Ada Pellegrini et al. Código de Defesa do Consumidor comentado pelos autores do anteprojeto, cit., p. 161.

(11)DENARI, Zelmo. Da qualidade de produtos e serviços, da prevenção e da reparação dos danos. In: GRINOVER, Ada Pellegrini et al. Código de Defesa do Consumidor comentado pelos autores do anteprojeto, cit., p. 164. 
O direito à saúde consta como um dos direitos básicos do consumidor, estando ao lado da proteção à vida e à segurança contra os riscos provocados por práticas no fornecimento de produtos e serviços considerados perigosos ou nocivos (art. 6으, I, CDC).

Ao tratar da Política Nacional de Relações de Consumo, o CDC, em seu art. 4ํ caput, elenca dentre os seus objetivos: o respeito à dignidade, saúde e segurança, a proteção dos interesses econômicos e a melhoria da qualidade de vida dos consumidores. Para alcançá-los estipula, nos incisos deste artigo, alguns princípios a serem atendidos. Cabe destacar o princípio que prevê a ação governamental no sentido de proteger o consumidor por meio da garantia do padrão de qualidade, segurança, durabilidade e desempenho de produtos e serviços (art. 4으, II, c). Neste aspecto, destacam-se as atribuições do SUS (Lei n. 8.080/90) e especificamente da ANVISA (Lei n. 9.782/99) em relação aos medicamentos.

No Capítulo IV do Título I, o CDC dispõe sobre a "Qualidade de produtos e serviços, da prevenção e da reparação dos danos" e na Seção I, trata especificamente "da proteção à saúde e segurança" com previsão, em seu art. $8^{\circ}$, de que

Os produtos e serviços colocados no mercado de consumo não acarretarão riscos à saúde ou segurança dos consumidores, exceto os considerados normais e previsíveis em decorrência de sua natureza e fruição, obrigando-se os fornecedores, em qualquer hipótese, a dar as informações necessárias e adequadas a seu respeito.

Os arts. 9o(12) e 10 ${ }^{\text {(13) }}$ do Código tratam, respectivamente, sobre a informação de produtos e serviços potencialmente nocivos ou perigosos à saúde e à segurança e sobre a colocação destes produtos ou serviços no mercado de consumo.

Diante destes dispositivos, destaca-se que a nocividade e periculosidade não induzem "defeito"(14). Um exemplo claro é que "a quase totalidade dos medicamentos, em razão de sua natureza, ostenta índice normal de nocividade que, com vistas à responsabilidade do fornecedor, será tolerado quando vier acompanhado de bulas explicativas"(15).

Após estes breves esclarecimentos acerca da tutela à saúde por meio do Código de Defesa do Consumidor, para analisar o pronunciamento da Corte de Cassação francesa sobre a responsabilidade de fabricante de medicamento com "defeito", deve-se partir, inicialmente, da compreensão de quem é "a vítima de evento", qual o tipo de responsabilidade prevista e o qual

(12) "Art. 9o O fornecedor de produtos e serviços potencialmente nocivos ou perigosos à saúde ou segurança deverá informar, de maneira ostensiva e adequada, a respeito da sua nocividade ou periculosidade, sem prejuízo da adoção de outras medidas cabíveis em cada caso concreto."

(13) "Art. 10. O fornecedor não poderá colocar no mercado de consumo produto ou serviço que sabe ou deveria saber apresentar alto grau de nocividade ou periculosidade à saúde ou segurança."

(14) Nas disposições seguintes, explica-se o significado do termo.

(15) GRINOVER, Ada Pellegrini et al., op. cit., p. 167. 
o significado de "defeito" tanto neste Código quanto no Código Civil francês. Após a explicação destes termos, elaborar-se-á uma breve apreciação do posicionamento da Corte frente a cada uma das decisões que emitiu.

O Código de Defesa do Consumidor apresenta quatro conceitos de consumidor. Um conceito padrão e três por equiparação. Dentre estes se encontra a "vítima do evento". O conceito standard pode ser encontrado nos artigos iniciais quando são definidos os elementos da relação contratual de consumo: consumidor final (art. $2^{\circ}$, caput) ${ }^{(16)}$, fornecedor (art. $\left.3^{\circ}\right)^{(17)}$, produto (art. $\left.3^{\circ}, \S 1^{\circ}\right)^{(18)}$ e serviço (art. $\left.3^{\circ}, \S 2^{\circ}\right)^{(19)}$.

O primeiro conceito por equiparação está disposto no art. $2^{\circ}$, parágrafo único, segundo o qual "equipara-se a consumidor a coletividade de pessoas, ainda que indetermináveis, que haja intervindo nas relações de consumo". O segundo, objeto do presente trabalho, consta do art. 17 que, para efeitos da seção sobre "a Responsabilidade pelo Fato do Produto e do Serviço", "equiparam-se aos consumidores todas as vítimas do evento". O terceiro conceito é aquele que, para efeitos do Capítulo sobre práticas comerciais e do Capítulo sobre proteção contratual "equiparam-se aos consumidores todas as pessoas determináveis ou não, expostas às práticas nele previstas".

Identifica-se facilmente, diante da análise ora proposta, que os três casos levados à Corte de Cassação francesa tratam de consumidor equiparado à vítima de evento danoso (art. 17, CDC) causado pelo fato do produto (medicamento). Apesar do Código Civil francês não se direcionar diretamente ao "consumidor", ele apresenta prescrição no mesmo sentido, em seu art. 1386-1, ao dispor que o produtor será responsável pelo dano causado por um defeito de seu produto, esteja ou não ligado à vítima por um contrato(20).

Estendendo as apreciações do ordenamento brasileiro para compreender o dispositivo ora retirado do Código Civil francês, percebe-se que em ambos os casos não importa se há ou não relação contratual de consumo. Ou seja, não há necessidade de as vítimas serem consumidoras diretas ${ }^{(21)}$. Tratam-se dos casos de propagação dos danos a terceiros estranhos à relação jurídica de consumo, também denominados de bystanders ${ }^{(22)}$.

(16) "Art. $2^{\circ}$ Consumidor é toda pessoa física ou jurídica que adquire ou utiliza produto ou serviço como destinatário final."

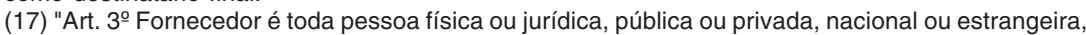
bem como os entes despersonalizados, que desenvolvem atividade de produção, montagem, criação, construção, transformação, importação, exportação, distribuição ou comercialização de produtos ou prestação de serviços."

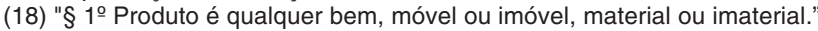

(19) "§ 2 o Serviço é qualquer atividade fornecida no mercado de consumo, mediante remuneração, inclusive as de natureza bancária, financeira, de crédito e securitária, salvo as decorrentes das relações de caráter trabalhista."

(20) CÓDIGO CIVIL FRANCÊS. Le service pulic de la diffusion du droit. 2003. Disponível em: $<$ www.legifrance.gouv. $\mathrm{fr} / \mathrm{html} /$ codes_traduits/somcives. $\mathrm{htm} \& \mathrm{sa}=\mathrm{X} \& \mathrm{oi}=$ translate\&resnum $=1 \& \mathrm{ct}=$ result\&prev=/search\%3Fq\%3Dcodigo\%2Bcivil\%2Bfrances\%2Barticulo\%2B1386\%26hl\%3DptBR\%26client\%3Dfirefox-a\%26channel\%3Ds\%26rls\%3Dorg.mozilla:pt-BR:official\%26sa\%3DG>. Acesso em: jul. 2008.

(21) NUNES, Luiz Antônio Rizzatto. Curso de direito do consumidor. 2. ed. São Paulo: Saraiva, 2005. p. 84.

(22) GRINOVER, Ada Pellegrini et al., op. cit., p. 199. 
Para a jurista espanhola Parra Lucan a figura do bystander demonstra a preocupação em impor ao fornecedor a obrigação de fabricar produtos seguros. Ela afirma ainda que 'toda regulamentação da responsabilidade pelo fato do produto, no âmbito da CEE, passa pelo conceito de segurança, a que todos têm direito'(23).

No CDC, é justamente na seção em que se encontra a previsão de consumidor equiparado à vítima de evento (art. 17) que está prevista a "responsabilidade pelo fato do produto e do serviço" causador do acidente de consumo. Para o caso em exame, cabe analisar o "fato do produto" e, para mais especificamente, do medicamento. O art. 12 do Código em questão prevê expressamente que:

O fabricante, o produtor, o construtor, nacional ou estrangeiro, e o importador respondem, independentemente da existência de culpa, pela reparação dos danos causados aos consumidores por defeitos decorrentes de projeto, fabricação, construção, montagem, fórmulas, manipulação, apresentação ou acondicionamento de seus produtos, bem como por informações insuficientes ou inadequadas sobre sua utilização e riscos. (grifo nosso)

Referido artigo trata da responsabilidade civil "objetiva"(24), ou seja, independente de culpa ${ }^{(25)}$ e derivada diretamente do "risco empresa"(26) (NORONHA). A preocupação do legislador foi de controlar o resultado da produção viciada/defeituosa, de forma a garantir ao consumidor o ressarcimento pelos prejuízos sofridos independentemente da figura do produtor/ fabricante que só será considerada na medida em que é o responsável pelo ressarcimento ${ }^{(27)}$.

A reparação de danos prevista na seção supramencionada do Código diz respeito à reparação de danos materiais, morais, estéticos e à imagem, que consiste em direito básico do consumidor (art. 6ํ, $\mathrm{VI}$ ). No entanto, para

(23) Apud Id. Ibid., p. 199.

(24) Tendo em vista o conteúdo do pronunciamento da Corte de Cassação francesa, não serão abordadas as responsabilidades administrativa e penal, apenas a civil. No entanto, ressalta-se que tratando-se de produtos defeituosos sujeitos à vigilância sanitária ou qualquer forma de controle e fiscalização governamental, cumpre à autoridade administrativa aplicar as sanções administrativas previstas no Código de Defesa do Consumidor, podendo consistir na apreensão ou inutilização do produto, na cassação do registro, na proibição de fabricação, suspensão de fornecimento etc. (GRINOVER, Ada Pellegrini et al., op. cit., p. 164; 172).

(25) Esta qualificação justifica-se pela dificuldade não só de demonstrar a culpa do fornecedor, mas também porque, às vezes, ele realmente não tem culpa pelo vício ou defeito do produto ou serviço. Há casos em que, mesmo que ele não aja de forma imprudente, negligente ou com imperícia, o produto ou serviço ainda pode apresentar vício ou defeito. Exemplo disto dá-se com a produção em série (NUNES, Luiz Antônio Rizzatto. op. cit., p. 158).

(26) Neste aspecto, Nunes ressalta que a livre-iniciativa para exploração da atividade econômica deve respeitar uma série de princípios, dispostos no art. 170 da Constituição Federal, dentre os quais se encontra a proteção do consumidor (inciso V) e que "uma das características principais da atividade econômica é o risco". O risco do negócio não deve ser assumido pelo consumidor, como ocorria antes do CDC entrar em vigor. A partir deste instituto legal, "o risco integral do negócio é do fornecedor" (2005, p. 153 a 159).

(27) NUNES, Luiz Antônio Rizzatto. op. cit., p. 156. 
haver responsabilidade de indenizar há necessidade de existência do nexo de causalidade "entre o consumidor (lesado), o produto e/ou serviço e o dano efetivamente ocorrente"(28).

O art. 1386-9 do Código Civil francês prevê que o demandante que deve provar o dano, o defeito e o nexo de causalidade entre 0 defeito e 0 dano. No direito brasileiro, apesar de não haver um dispositivo legal prevendo esta incumbência para o consumidor é a ele, "naturalmente, a quem incumbe a prova do dano, do nexo de causalidade entre o dano e o produto, com a indicação do responsável pela fabricação do produto". No entanto, o CDC possibilita, como um direito básico do consumidor, a inversão do ônus de produzir essa prova nas hipóteses do inciso VIII do art. $6^{\mathrm{o}(29)}$.

Resta saber em que consistem os defeitos citados no caput do art. 12 do Código de Defesa do Consumidor e na decisão da Corte de Cassação francesa. Para tanto, é necessário compreender os $\S \S 1^{\circ}$ e $2^{\circ}$ do art. 12 do CDC - que "reproduz, literalmente, o art. 6 da Diretiva n. 374/85 da CEE"(30) e 0 art. 1386-4 do Código Francês ${ }^{(31)}$ :

$\S 1^{\circ} \mathrm{O}$ produto é defeituoso quando não oferece a segurança que dele legitimamente se espera, levando-se em consideração as circunstâncias relevantes, entre as quais:

I - sua apresentação;

II - o uso e os riscos que razoavelmente dele se esperam;

III - a época em que foi colocado em circulação.

$\S 2^{\circ}$ O produto não é considerado defeituoso pelo fato de outro de melhor qualidade ter sido colocado no mercado.

Apesar de alguns doutrinadores, a exemplo dos autores do pré-projeto do Código de Defesa do Consumidor, não considerarem a dicotomia estabelecida entre vício e defeito(32), adota-se, para considerar a decisão da Corte de Cassação, a doutrina que distingue os dois termos.

Rizzatto Nunes dispõe sobre esta distinção. Para ele, os vícios são "as características de qualidade ou quantidade que tornem os produtos ou serviços impróprios ou inadequados ao consumo a que se destinam e também que Ihes diminuam o valor" assim como aqueles que decorrem de "disparidade havida em relação às indicações constantes do recipiente, embalagem, rotulagem, oferta ou mensagem publicitária"(33).

Para este autor, os defeitos pressupõem o vício. No entanto, este é inerente ao produto e serviço, não atinge a pessoa ou bens do consumidor.

(28) Id. Ibid., p. 160, 162.

(29) Id. Ibid.

(30) GRINOVER, Ada Pellegrini et al., op. cit., p 185.

(31) CÓDIGO CIVIL FRANCÊS. Le service pulic de La diffusion du droit, cit.

(32) GRINOVER, Ada Pellegrini et al., op. cit., p 175.

(33) NUNES, Luiz Antônio Rizzatto. op. cit., p. 166. 
Enquanto aqueles ultrapassam os produtos e serviços e atingem a pessoa do consumidor em "seu patrimônio jurídico mais amplo (seja moral, material, estético ou de imagem)"(34). Este entendimento pode ser extraído da leitura do art. 1386-2 do Código Civil francês, que preceitua que as disposições do título sobre "a responsabilidade por produtos defeituosos" serão aplicadas para o dano que resulte de um atentado contra a pessoa ou de um bem diferente ao produto defeituoso(35).

Frente a este posicionamento constata-se que o acidente de consumo ${ }^{(36)}$ pressupõe um defeito do produto ou do serviço e não um vício(37). Não por acaso, o Código de Defesa do Consumidor tratou dos defeitos na seção sobre "a responsabilidade pelo fato do produto e do serviço", já citada acima, e dos vícios quantidade e de qualidade na seção sobre a "responsabilidade por vício do produto e do serviço".

Outro tema abordado na decisão da Corte de Cassação e que apresenta não só semelhanças, mas também pontos divergentes frente ao Direito do Consumidor brasileiro, diz respeito às excludentes do nexo de causalidade ${ }^{(38)}$. Neste ponto, o CDC foi mais restritivo que o Código Civil francês (art. 1386-11) e este, por sua vez, restringiu a previsão de Diretiva da CEE de 1985(39).

De acordo com o art. $7^{\circ}$ desta Diretiva, o produtor não será responsável pelo dano se provar:

a) que no puso el producto en circulación;

b) o que, teniendo en cuenta las circunstancias, sea probable que el defecto que causó el daño no existiera en el momento en que él puso el producto en circulación o que este defecto apareciera más tarde;

c) o que él no fabricó el producto para venderlo o distribuirlo de alguna forma con fines económicos, y que no lo fabricó ni distribuyó en el ámbito de su actividad profesional;

d) o que el defecto se debe a que el producto se ajusta a normas imperativas dictadas por los poderes públicos;

(34) NUNES, Luiz Antônio Rizzatto. op. cit., p. 167.

(35) CÓDIGO CIVIL FRANCÊS. Le service pulic de La diffusion du droit, cit.

(36) "Diga-se, de qualquer maneira, que se tem usado tanto 'fato do produto e do serviço' quanto 'acidente de consumo', para definir o defeito. Porém, o mais adequado é guardar a expressão 'acidente de consumo' para as hipóteses em que tenha ocorrido mesmo um acidente: queda de um avião, batida de veículo por falta de freio, etc. e deixar fato ou defeito às demais ocorrências danosas. Em qualquer hipótese, aplica-se a lei" (NUNES, Luiz Antônio Rizzatto. op. cit., p. 258).

(37) NUNES, Luiz Antônio Rizzatto. op. cit., p. 167.

(38) "[...] não se trata de excludente de responsabilidade, como se tem dito, mas sim de excludente do nexo de causalidade. O que pode o fornecedor fazer é buscar desconectar a relação acidentária consigo, isto é, tentar excluir o nexo de causalidade existente entre ele - fornecedor - e o dano/ defeito." (NUNES, Luiz Antônio Rizzatto. op. cit., p. 270)

(39) DIRECTIVA 85/374/CEE. Directiva del Consejo de 25 de julio de 1985 relativa a la aproximación de las disposiciones legales, reglamentarias y administrativas de los Estados miembros en materia de responsabilidad por los daños causados por productos defectuosos. 1985. Disponível em: <http:// www.davara.com/documentos/relacionados/consumer/Dir_85374CEE.pdf>. Acesso em: jul. 2008. 
e) o que, en el momento en que el producto fue puesto en circulación, el estado de los conocimientos científicos y técnicos no permitía descubrir la existencia del defecto;

f) o que, en el caso del fabricante de una parte integrante, el defecto sea imputable al diseño del producto a que se ha incorporado o a las instrucciones dadas por el fabricante del producto. ${ }^{(40)}$

Apesar disto, a Diretiva possibilitou, por meio de seu art. 15 "b" que, não obstante a previsão do art. 7ํ "e", os Estados-membros podem dispor em sua legislação que o produtor seja responsável inclusive se demonstrar que, no momento em que colocou o produto em circulação, o estado de conhecimentos científicos e técnicos não permitia detectar a existência do defeito(41). Neste sentido, a Diretiva permitiu que alguns Estados-membros adotassem o regime total de exclusão da responsabilidade pelo risco de desenvolvimento, o regime parcial ou o regime de responsabilização total.

Desta forma, da observação do art. 1386-11 em conjunto com o art. 138612, percebe-se que o Código Civil francês adotou o regime parcial de responsabilização pelo risco de desenvolvimento(42). $\mathrm{O}$ art. 1386-11 dispõe que:

El productor será responsable de pleno derecho a menos que pruebe:

$1{ }^{\circ}$ Que no había puesto el producto en circulación;

$2^{\circ}$ Que, teniendo en cuenta las circunstancias, proceda estimar que el defecto que hubiera causado el daño, no existía en el momento en que el producto fue puesto en circulación por él o que ese defecto hubiera nacido posteriormente;

$3^{\circ}$ Que el producto no estaba destinado a la venta o a cualquier otra forma de distribución;

4- Que el estado de los conocimientos científicos y técnicos, en el momento en que puso el producto en circulación, no permitió descubrir la existencia del defecto;

$5^{\circ} \mathrm{O}$ que el defecto fuera debido a la conformidad del producto con las reglas imperativas de orden legislativo o reglamentario. ${ }^{(43)}$

Os casos de incidência de tal responsabilidade, apenas em casos específicos, estão previstos no art. 1386-12 do Código Civil francês, segundo o qual o produtor não poderá invocar a causa de exoneração prevista na parte 4⿳亠丷厂 do art. 1386-11 quando o dano tenha sido causado por um elemento do corpo humano ou por produtos resultantes deste.

(40) DIRECTIVA 85/374/CEE. Directiva del Consejo de 25 de julio de 1985 relativa a la aproximación de las disposiciones legales, reglamentarias y administrativas de los Estados miembros en materia de responsabilidad por los daños causados por productos defectuosos, cit.

(41) DIRECTIVA 85/374/CEE. Directiva del Consejo de 25 de julio de 1985 relativa a la aproximación de las disposiciones legales, reglamentarias y administrativas de los Estados miembros en materia de responsabilidad por los daños causados por productos defectuosos, cit.

(42) SILVA, Marco Aurélio Lopes Ferreira. Responsabilidade pelo risco de desenvolvimento. Revista da Faculdade de Direito de Campos, ano 7, n. 8, p. 6-7, jun. 2006. Disponível em: <http://www.fdc.br/ Arquivos/Mestrado/Revistas/Revista08/Discente/MarcoAurelio.pdf>. Acesso em: ago. 2008.

(43) CÓDIGO CIVIL FRANCÊS. Le service pulic de La diffusion du droit, cit. 
O CDC prevê de forma taxativa(44), e mais restritiva que as normas ora citadas, as causas excludentes do nexo de causalidade, que são indicadas no art. 12, § 3ㅇ:

$\S 3^{\circ} \mathrm{O}$ fabricante, o construtor, o produtor ou importador só não será responsabilizado quando provar:

I - que não colocou o produto no mercado;

II - que, embora haja colocado o produto no mercado, o defeito inexiste;

III - a culpa exclusiva do consumidor ou de terceiro.

Como este instituto jurídico não abordou de forma expressa a responsabilidade em virtude do risco de desenvolvimento, esta temática apresentase bastante polêmica, havendo posicionamentos doutrinários contra e a favor à exclusão da responsabilização do produtor nestes $\operatorname{casos}^{(45)}$.

Diante do quadro ora apresentado, que relata brevemente algumas similaridades entre o CDC e o Código Civil francês em relação à responsabilidade do fabricante/produtor por produtos defeituosos, tecer-se-ão alguns comentários acerca da Decisão da Corte de Cassação francesa.

Já foi observado que os três casos apresentados à Corte de Cassação tratavam de vítimas de evento causado por defeito de medicamento. No entanto, percebe-se que o pronunciamento desta Corte para cada um dos casos possui uma peculiaridade.

No primeiro caso, diante da reiteração da decisão da Corte de Apelação, que condenou o laboratório em virtude do evento danoso provocado por seu medicamento, percebe-se a ênfase que a Corte de Cassação deu ao fundamento presente no art. 1386-9 do Código Civil francês - acima citado — ao ressaltar que a existência de nexo causal entre o dano provocado e a administração do produto deve ser constatada a partir de presunções graves, precisas e concordantes. Como já apontado, no direito do consumidor brasileiro também há a exigência deste nexo de causalidade para que haja o regime de responsabilização pelos danos causados às vítimas do evento.

No segundo caso, pelo pronunciamento da Corte de Cassação, podese constatar que sua decisão de cassar a decisão da Corte de Apelação e considerar insuficientes as constatações apresentadas para caracterizar o "defeito do produto" pautou-se no art. 1386-4 do Código Civil francês, já que sua argumentação baseia-se na idéia de que o produto, quando colocado no mercado de consumo, oferecia a segurança que dele legitimamente se esperava. Diante da atenção dada à "caracterização do defeito do produto",

(44) NUNES, Luiz Antônio Rizzatto. op. cit., p. 270.

(45) Não cabe, no presente trabalho, abordar esta problemática. No entanto, ressalta-se a necessidade de interpretação de cada caso concreto em conformidade com os princípios de proteção do consumidor, dentre os quais o de vulnerabilidade. SILVA, Marco Aurélio Lopes Ferreira. op. cit. 
não se verificou manifestação da Corte acerca do risco de desenvolvimento (art. 1386-11, 4ํ) como causa para descartar a responsabilidade do fabricante pelo dano causado pela sua vacina. Comparando com o direito do consumidor brasileiro pode-se perceber que o regime para caracterização do defeito é o mesmo, tendo o art. 12 , $\S \S 1^{\circ}$ e $2^{\circ}$, reproduzido a previsão legal do 1386-4 do Código Francês. No que diz respeito à responsabilização pelo risco de desenvolvimento, verificou-se que se trata de assunto polêmico na doutrina consumerista brasileira.

No último caso que analisou, a Corte de Cassação manteve a decisão da Corte de Apelação no sentido de responsabilizar o fabricante de hormônio de crescimento que levou os pacientes a contraírem a doença de Creutzfeldt Jakob. Para fundamentar estes posicionamentos, ambas as Cortes afastaram a aplicação do art. 11 da Diretiva 85/374, que prevê a extinção dos direitos da vítima em 10 anos após a colocação do produto no mercado de consumo. Elas afirmaram que na data em que os produtos foram colocados em circulação (fevereiro de 1985), a Diretiva ora citada não estava em vigor (Diretiva 85/375 de julho de 1985).

Desta forma, ambas apontaram que a base legal para tais decisões estava presente nos arts. 1.347 e 1.382 do Código Civil francês que dizem respeito à reparação do dano com base na prova da "culpa" do fabricante, tendo em vista a sua imprudência na extração, purificação e composição dos hormônios. Por meio deste regime de responsabilidade, a Corte de Cassação afastou qualquer tentativa de utilização de causas exoneratórias previstas no art. 1386-11 do Código Civil francês, que transpôs a Diretiva de 1985. A Corte de Cassação reiterou também a consideração da Corte de Apelação acerca da existência do nexo de causalidade entre a doença e o hormônio de crescimento. Neste aspecto, não há previsão expressa no CDC sobre o prazo de prescrição dos direitos das vítimas de evento em decorrência do fato do produto.

\section{REFERÊNCIAS BIBLIOGRÁFICAS}

ALMEIDA, João Batista de. A proteção jurídica do consumidor. 2. ed. atual. e ampl. São Paulo: Saraiva, 2000.

BENJAMIN, Antônio Herman de Vasconcellos e. O código brasileiro de proteção ao consumidor. 1993. Disponível em: <http://bdjur.stj.gov.br/dspace/ bitstream/2011/9471/1/O_C\%C3\%B3digo_Brasileiro_Prote\%C3\%A7\%C3\% A3o_Consumidor.pdf>. Acesso em: jul. 2008.

BRASIL. Manual de direito sanitário com enfoque na vigilância em saúde. Brasília: Ministério da Saúde, 2006.

BRASIL. Constituição Federal de 1988. Disponível em: <http://www.planalto.gov.br/ ccivil_03/Constituicao/Constitui\%E7ao.htm>. Acesso em: ago. 2008. 
BRASIL. Lei n. 8.080, de 13 de setembro de 1990. Dispõe sobre as condições para a promoção, proteção e recuperação da saúde, a organização e o funcionamento dos serviços correspondentes e dá outras providências. Disponível em: <http://www.planalto.gov.br/ccivil_03/Leis/L8080.htm>. Acesso em: jun. 2008.

CÓDIGO CIVIL FRANCÊS. Le service pulic de La diffusion du droit. 2003. Disponível em: <www.legifrance.gouv.fr/html/codes_traduits/somcives.htm\& $\mathrm{sa}=\mathrm{X} \&$ oi=translate\&resnum $=1 \& \mathrm{ct}=$ result\&prev=/search $\% 3 \mathrm{Fq} \% 3 \mathrm{Dcodigo} \% 2$ Bcivil\%2Bfrances\%2Barticulo\%2B1386\%26hl\%3Dpt-BR\%26client\%3Dfirefox -a\%26channel\%3Ds\%26rls\%3Dorg.mozilla:pt-BR:official\%26sa\%3DG>. Acesso em: jul. 2008.

DENARI, Zelmo. Da qualidade de produtos e serviços, da prevenção e da reparação dos danos. In: GRINOVER, Ada Pellegrini et al. Código de Defesa do Consumidor comentado pelos autores do anteprojeto. 8 ed. Rio de Janeiro: Forense, 2005.

DIRECTIVA 85/374/CEE. Directiva del Consejo de 25 de julio de 1985 relativa a la aproximación de las disposiciones legales, reglamentarias y administrativas de los Estados miembros en materia de responsabilidad por los daños causados por productos defectuosos. 1985. Disponível em: <http:// www.davara.com/documentos/relacionados/consumer/Dir_85374CEE.pdf>. Acesso em: jul. 2008.

FILOMENO, José Geraldo Brito. Dos direitos do consumidor. In: GRINOVER, Ada Pellegrini et al. Código de Defesa do Consumidor comentado pelos autores do anteprojeto. 7. ed. Rio de Janeiro, 2001.

GRINOVER, Ada Pellegrini et al. Código de Defesa do Consumidor comentado pelos autores do anteprojeto. 8 ed. Rio de Janeiro: Forense, 2005.

NORONHA, Fernando. Direito do consumidor: contratos de consumo, cláusulas abusivas e responsabilidade do fornecedor. Apostila. [S.L.], [s.d.].

NUNES, Luiz Antônio Rizzatto. Curso de direito do consumidor. 2. ed. São Paulo: Saraiva, 2005.

OLIVEIRA, Mariana Siqueira de Carvalho. Por uma construção democrática do direito à saúde: a Constituição Federal, os instrumentos de participação social e a experiência do Conselho Nacional de Saúde. 2005. Dissertação (Mestrado em Direito) - Programa de Pós-Graduação em Direito, Faculdade de Direito, Universidade de Brasília, Brasília, 2005.

SILVA, Marco Aurélio Lopes Ferreira. Responsabilidade pelo risco de desenvolvimento. Revista da Faculdade de Direito de Campos, ano 7, n. 8, jun. 2006. Disponível em: <http://www.fdc.br/Arquivos/Mestrado/Revistas/Revista08/Discente/MarcoAurelio.pdf>. Acesso em: ago. 2008. 